Article

\title{
The Long-term Sustainability of Lean as a Management Practice: Survey Evidence on Diffusion and Use of the Concept in Norway in the Period 2015-2017
}

\author{
Dag Øivind Madsen ${ }^{1, * \mathbb{C}}$, Terje Berg ${ }^{2}$, Tonny Stenheim ${ }^{1}$, Janne Vagnild Moum ${ }^{2}$, \\ Inger Overland Bordewich ${ }^{2}$ and Maria Storsveen ${ }^{3}$ \\ 1 Department of Business, Marketing and Law, School of Business, University of South-Eastern Norway, \\ Bredalsveien 14, 3511 Hønefoss, Norway; tonny.stenheim@usn.no \\ 2 NTNU Business School, Norwegian University of Science and Technology, Klæbuveien 72, 7491 Trondheim, \\ Norway; terje.berg@ntnu.no (T.B.); jannemou@gmail.com (J.V.M.); inger.overland@gmail.com (I.O.B.) \\ 3 School of Economics and Business, Norwegian University of Life Sciences, Chr. Magnus Falsens vei 18, \\ 1430 Ås, Norway; maria_storsveen@live.no \\ * Correspondence: dagm@usn.no
}

Received: 24 April 2019; Accepted: 24 May 2019; Published: 3 June 2019

check for updates

\begin{abstract}
Even though Lean is a management concept with roots stretching back several decades, it did not take off on a large scale in Norway until around 2010. Since then, Lean has received frequent attention in the Norwegian media, and recent surveys indicate that the diffusion and popularity of Lean can be considered relatively high in both the private and public sectors. This article focuses on the sustainability of Lean as a management practice in Norway. The Google dictionary defines the term "sustainability" as "the ability to be maintained at a certain rate or level." The article therefore seeks to examine the evolution in the diffusion and use of the Lean concept in Norway in the period 2015-2017. For this purpose, we draw on data from two surveys administered in 2015 and 2017, as well as a small number of follow-up interviews carried out in 2017. The results generally show that the diffusion rate in Norway appears to be relatively stable, and Lean users appear to have a very positive perception of the concept, which indicates that the Lean concept currently has an institutionalised position as a management practice in Norway. Therefore, the evolution pattern of Lean in Norway differs from what has been observed in other countries where the concept appears to be on a downward trajectory in terms of its popularity. Moreover, the results reveal considerable variation in terms of how Lean is interpreted, understood and used in practice, for instance, when it comes to abstraction levels and the use of different Lean-related principles and tools. Overall, the results have several theoretical and methodological implications for future studies on the diffusion, use and long-term sustainability of popular management concepts such as Lean.
\end{abstract}

Keywords: lean; management concept; diffusion; use; sustainability; management practice; popularity

\section{Introduction}

Lean is a Japanese-inspired management concept which seeks to improve and simplify production processes to reduce waste and improve organisational productivity. As a management concept, Lean emerged strongly in the early 1990s in the aftermath of the release of the management bestseller The Machine That Changed the World, a book centred around the merits of the Toyota Production System [1]. Since the 1990s, Lean has been adopted all around the world and has garnered a large following [2,3]. However, the observed popularity of Lean has varied over time. For example, Lean has 
at times been so popular that it has been referred to as a management fashion in countries such as Germany [4] and Sweden [5]. The surveys carried out by consulting firm Bain \& Company about trends in the use of management tools paint a different picture, demonstrating the downward sloping trend of Lean's global popularity; additionally, Lean has not featured in the top 25 most popular management tools during the last decade [6,7]. In recent times, it has been overshadowed by newer concepts and buzzwords such as Agile Management and Big Data Analytics [8].

In Norway, however, there are signs indicating that Lean is on an upward trajectory in terms of its diffusion and popularity. In recent years, Lean has received significant attention in Norwegian work and business life $[9,10]$, and it has been pointed out that the popularity of Lean has reached pandemic proportions [11]. Surveys and case studies generally show that the use of Lean is widespread in both private and public sector organisations [9,12-19]. At the same time, these studies indicate that Lean is used in different ways and that different actors apply the Lean concept (e.g., different Lean-related principles and tools) to different degrees $[14,17,20]$. In other words, Lean is a concept, which is continuously interpreted and translated as it is applied and put to use in organisational practice $[13,21,22]$.

Since previous studies indicate that the diffusion and use of Lean varies across time and space, it is compelling to comprehensively examine the evolutionary trajectory of Lean in Norway. This article, therefore, presents the results of a survey that was carried out in 2017 to replicate and expand a survey from 2015 [23]. The purpose of the study is to provide an updated picture of the status of the diffusion and use of Lean, and to assess the long-term sustainability of Lean as a management practice in Norway. The dictionary defines "sustainability" as "the ability to be maintained at a certain rate or level". With this as a backdrop, the article is guided by the following overall research question: To what extent does the Lean concept have long-term sustainability as a management practice in Norway?

The rest of the article is structured as follows. First, we provide a short introduction to the concept of Lean, with a focus on the Norwegian context. Thereafter, we outline the methodological approach followed in the empirical section of the article before we turn to the presentation of the results of the surveys. We conclude the article with the identification of limitations and ideas for future research into the diffusion, use and sustainability of Lean.

\section{The Diffusion, Use and Sustainability of Lean in Norway}

\subsection{The Concept of Lean}

Lean is often understood as a set of tools or techniques that can contribute to the identification of waste and reduction of organisational inefficiencies. In this way, implementing Lean can help to produce higher quality products and services using fewer resources.

The concept of Lean has roots which stretch back several decades, and providing a detailed account of the history of the Lean concept is a complicated exercise [24]. There is, however, a broad consensus among researchers that Lean received its big break during the late 1980s and early 1990s in the aftermath of Krafcik's MIT Sloan Management Review article "Triumph of the Lean Production System" and Womack, Jones and Roos' book The Machine That Changed The World [1,25]. The source of inspiration for the Lean concept was years of experience and insight from the Japanese car manufacturer Toyota.

In the beginning, the focus of the Lean literature was firmly on conventional industrial production (Lean Production), but today there are a wide variety of adaptations of generic Lean thinking suited to different industries and contexts such as construction, health, finance and accounting (e.g., Lean Construction, Lean Healthcare and Lean Accounting). A search of the Scopus database shows that there has been a significant increase in the number of articles about different forms of Lean in the period 1992-2018. Figure 1 shows the number of articles with the different forms of Lean mentioned in the article title. 


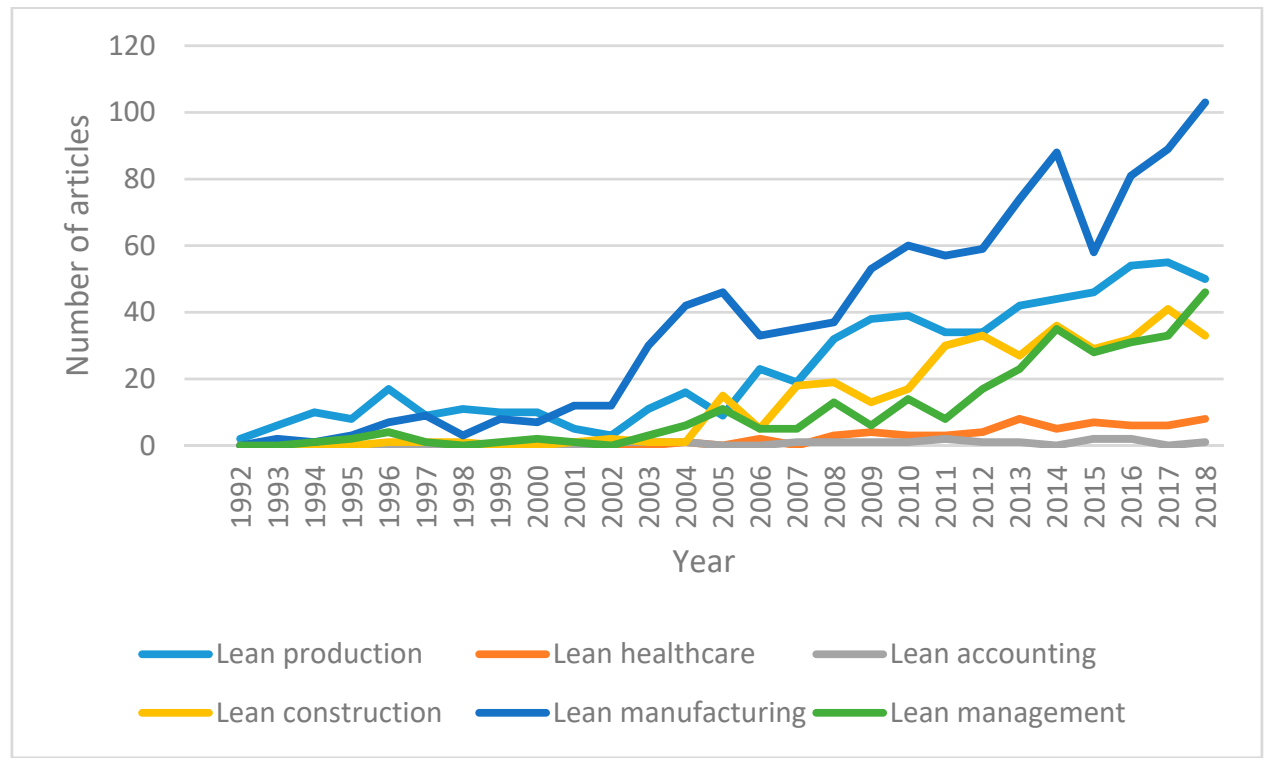

Figure 1. Articles about different forms of Lean in the SCOPUS database.

The fact that the Lean concept is presented and applied in such distinct ways makes it quite challenging to define the concept. As a result, many researchers have commented that Lean can be interpreted and understood in different ways, in practice $[2,4,26,27]$. For example, Ingvaldsen, Ringen and Rolfsen [20] argue that Lean can be understood in four main ways: as (1) an organisational trend, (2) a management philosophy, (3) a set of principles or (4) a set of practices. Viewing Lean as a management philosophy means that one places the most weight on the cultural aspects of Lean and how it affects the informal part of the management and governance of an organisation. In contrast, viewing Lean as a set of practices means that one puts more emphasis on the direct manifestations of Lean in an organisation, as a result of the use of tools and techniques such as Poka-Yoke, Kanban, SMED and value stream mapping. Modig and Åhlström [28] argue that the differences in interpreting and understanding Lean are due to different abstraction levels. Some Lean users view it as an abstract concept (e.g., philosophy or culture), while others have a stronger emphasis on the use of concrete Lean-related tools and techniques.

\subsection{Diffusion and use of Lean in Norway}

Researchers have pointed out that the Japanese-inspired Lean concept has "travelled" all around the world [20], for example to countries such as Germany and Sweden [4,5]. Although Lean-inspired ideas have been used in Norwegian industry for quite some time [9,15], Lean did not "take off" on a large scale in Norway until around 2009-2010 when Lean Forum Norge was established and started various activities to promote the concept and practice of Lean [9]. Lean Forum Norway has spearheaded the development of an infrastructure supporting Lean in Norway by establishing an annual conference and a best practice award, as well as regional networks and meeting places. This has contributed to the Lean movement's strong Norwegian foothold [3,14].

Since around 2010, there has been a rapid spread of Lean reaching pandemic proportions [11]. Surveys indicate that Lean, in a relatively short period of time, has become widely used in not only private, but also public organisations [17-19]. As a whole, these studies suggest that Lean has had a sharp upswing in popularity in Norway.

Researchers have also focused on how the Lean concept is used in the Norwegian context. For example, a number of factors idiosyncratic to Norway (and Scandinavia), such as a high degree of industrial democracy as well as the tripartism model, emphasising collaboration between employers, unions, and the government; play a role in how a global management concept such as Lean is interpreted and applied [21]. Researchers have observed that a more "democratic" form of Lean 
has evolved in Norway; this evolution is more in tune with the local work-life model and business culture $[9,10,29]$. This democratisation of Lean can be attributed to, for example, the influential role played by unions [30].

Studies indicate that Lean is interpreted and used in different ways in Norway. For example, empirical data from Norwegian municipalities reveal considerable variations in the use of Lean, e.g., in terms of the Lean-related tools/techniques organisations use. We can observe similar developments in the private sector. For instance, among industrial production firms, there is not a uniform understanding of Lean; instead, different actors choose the elements of the concept that they think fit their own circumstances and interests [14].

\subsection{The Sustainability of Lean}

In recent years, the concept of Lean has increasingly been linked to the term sustainability. As Jørgensen, et al. [31], p. 372 point out, there are basically two ways of discussing Lean in the context of sustainability: (1) by looking at how Lean is linked to ecological and environmental sustainability, or (2) looking at whether the concept of Lean itself is sustainable in the long-run.

With respect to the former, the focus of this literature is on how Lean can facilitate ecological and environmental preservation by reducing waste and conserving resources. Considerable literature has shown that the concept of Lean is increasingly being used in organizational efforts and initiatives to become to more ecologically and environmentally sustainable [32-37].

With respect to the latter, the focus is on the concept of Lean itself. The general question concerns whether the use of the concept is sustainable in the long-run, meaning that the interest and momentum of the concept can be sustained long enough for organizations to learn and develop the necessary capabilities to realise potential benefits. Considerable research has focused on themes broadly related to the implementation and use of Lean, and evidence has shown that it can be difficult to achieve success in Lean implementation due to lack of managerial commitment, poor communication, cultural mismatch, or organizational resistance, to name just a few critical factors [38-44].

\subsection{Summary}

This brief literature review has shown that the concept of Lean is elusive and can be interpreted and understood in different ways. Studies carried out in Norway show that the uptake of the concept differs both in terms of diffusion and use, and that the current level of popularity appears to be fairly high. It is, therefore, pertinent to ask the question of whether this level of popularity can be sustained at the current level, and there are several issues related to both the diffusion, use and sustainability of the Lean concept that should be examined empirically.

In the next section, we will turn our attention to how we will empirically examine the evolution of the diffusion and use of Lean in Norway.

\section{Methods and Data}

This study primarily draws on quantitative survey data. The primary data source comprises two cross-sectional surveys which were administered during the winters of 2015 and 2017, as part of two master's degree thesis projects $[45,46]$.

We chose to carry out surveys since the overall aim of the study was to map the diffusion and use of Lean. One strength of the survey method is that it is possible to collect data from a large number of respondents [47]. Additionally, by conducting qualitative follow-up interviews it should be possible to obtain a deeper understanding of how Lean is interpreted and used.

\subsection{The Two Surveys}

Information about Norwegian firms and their contact information (email addresses) were collected from the Proff Forvalt company database. We administered the survey using the survey software 
packages Questback (2015) and SelectSurvey (2017). Electronic surveys have key advantages related to cost-effectiveness and speediness [48].

Table 1 summarises the response rates in the two surveys, which were $10.7 \%$ (2017) and $10.9 \%$ (2015). According to established norms in the research methods literature, this is generally considered to be quite low [49]. On the other hand, studies undertaken in recent years show that electronic surveys tend to yield considerably lower response rates than traditional postal surveys [50,51].

Table 1. Responses in the 2015 and 2017 surveys.

\begin{tabular}{ccccc}
\hline & \multicolumn{2}{c}{2017} & \multicolumn{2}{c}{$\mathbf{2 0 1 5}$} \\
\hline Respondents & Number & Percentage & Number & Percentage \\
Completed & 1886 & 10.7 & 1220 & 10.9 \\
Not completed & 197 & 1.1 & 99 & 0.9 \\
Declined & 285 & 1.5 & 342 & 3.0 \\
Non-response & 15,146 & 86.2 & 9503 & 84.7 \\
E-mail response & 68 & 0.3 & 54 & 0.5 \\
Total & $\mathbf{1 7 , 5 8 2}$ & $\mathbf{1 0 0}$ & $\mathbf{1 1 , 2 1 8}$ & $\mathbf{1 0 0}$ \\
\hline
\end{tabular}

There are several factors, which may explain the relatively low-response rate in our survey. First of all, the survey was targeted at an extensive group of respondents. Moreover, there may be a general fatigue in the business community when it comes to answering questionnaires, so-called survey fatigue [52]. For example, one of the respondents answered in an email that "just in the last five days I have received five requests to participate in surveys". Therefore, this could partly reflect a trend and "sign of our times", which presents a general problem when using the survey method. However, as a whole, these issues should not be taken lightly since they could contribute to challenges with respect to so-called non-response bias.

\subsection{Survey and Interviews}

The questionnaires consisted of several parts, covering, for example, knowledge and awareness; adoption motives and implementation; as well as positive and negative experiences of the use of Lean. Most of the questions were closed-ended and used a seven-point Likert scale. For some of the questions, it was possible for the respondents to select up to three alternatives. This means that for some of the tables in this article the sums will exceed $100 \%$. In order to ensure validity and reliability, the questions were pretested both in 2015 and 2017.

The questionnaire used in 2015 consisted of 32 questions, while in 2017 it was expanded to 36 questions. The additional questions centered on the level of abstraction in Lean thinking. For example, one new question was formulated as "What does Lean mean to you?" The full questionnaires are available (in Norwegian) as appendices in the two master's theses, which are available via institutional repositories [45,46].

One of the background questions attempted to obtain information about the respondent's role in the firm. The typical respondent was the general manager (e.g., Chief Executive Officer) or financial manager (e.g., Chief Financial Officer). Therefore, there is reason to believe that the respondents were familiar with their own organisation and the use of Lean, as well as other similar management concepts and tools. Still, it should be pointed out that we in this survey let the respondents speak on behalf of their organisation, and it is possible that the view of the respondent may not be representative of the rest of the organisation. Moreover, there may also have been different interpretations and understandings of the questions across respondents. We will discuss these methodological issues in more detail towards the end of the article.

In both 2015 and 2017, we used a dynamic questionnaire, which means that the questions were adapted to each respondent based on their answers to a previous question. For example, the survey ended if the respondents answered "no" to the question of whether they had heard of Lean. Thus, the subsamples of respondents answering each question (or set of questions) in the questionnaire may 
differ from the total sample of respondents completing the questionnaires (in 2015: 1220; in 2017: 1886), which is important to keep in mind when interpreting the results.

We also carried out six interviews to cast additional light on the answers from the 2017 survey (for details, see Table 2). We developed an interview guide with open questions sorted according to different categories. All of the interviews were conducted face-to-face at the respondents' business location.

Table 2. Details about interviewees.

\begin{tabular}{ccccc}
\hline Interviewees & Branch & Date & Duration & Time Since Implementation \\
\hline 1 & IT & $24^{\text {th }}$ March 2017 & $38 \mathrm{~min}$. & 10 years \\
2 & Banking & $29^{\text {th }}$ March 2017 & $1 \mathrm{~h} 16 \mathrm{~min}$. & 4 years \\
3 & Real estate broking & $30^{\text {th }}$ March 2017 & $37 \mathrm{~min}$. & 8 years \\
4 & Oil and gas & $17^{\text {th }}$ March 2017 & $30 \mathrm{~min}$. & 2 years \\
5 & Construction & $19^{\text {th }}$ March 2017 & $1 \mathrm{~h} 2 \mathrm{~min}$. & 14 years \\
6 & Insurance & $19^{\text {th }}$ March 2017 & $31 \mathrm{~min}$. & 4 years \\
\hline
\end{tabular}

\section{Results}

\subsection{Knowledge and Awareness}

When comparing the numbers in Table 3, we see that there has been a small increase in the awareness of Lean. One potential explanation of this is that during these two years the Lean concept has "travelled" further [20]. In addition, the 2017 survey demonstrates that there is greater awareness among the larger organisations than among the small. At the same time, it should be noted that the relative increase among the smallest firms (1-9 employees) is $26 \%$.

Table 3. Knowledge/awareness and organisational size.

\begin{tabular}{ccccc}
\hline & \multicolumn{2}{c}{$\mathbf{2 0 1 7}$} & \multicolumn{2}{c}{$\mathbf{2 0 1 5}$} \\
\hline Number of employees & $\mathbf{N}$ & Awareness (\%) & $\mathbf{N}$ & Awareness (\%) \\
$1-9$ & 436 & 34.4 & 128 & 27.3 \\
$10-49$ & 1,136 & 57.5 & 786 & 51.3 \\
$50-99$ & 183 & 75.4 & 135 & 69.6 \\
$100-249$ & 128 & 83.6 & 95 & 92.6 \\
$250+$ & 103 & 90.3 & 72 & 91.7 \\
Do not know & 39 & 53.8 & 4 & 25.0 \\
Total & & $\mathbf{5 7 . 4}$ & $\mathbf{1 2 2 0}$ & $\mathbf{5 6 . 3}$ \\
\hline
\end{tabular}

\subsection{Contact Points}

In order to obtain a clearer picture of the diffusion pattern of Lean in Norway, we asked the respondents how they came into contact with the Lean concept. Their answers are able to reveal what types of channels of diffusion and supply side actors have been active in the Norwegian market and could be considered central to the diffusion process. Table 4 illustrates that there is a comparatively high degree of stability in terms of the relative importance of different diffusion channels, but that there have been a number of smaller changes over time. For example, business media has gone from third place to the most common channel for exposure to Lean. This finding could be connected to the substantial increase in Lean public management discourse in the Norwegian media in recent years, in which there has been a flurry of articles about organisations who have implemented Lean [23] 
Table 4. Contact points with Lean.

\begin{tabular}{|c|c|c|c|c|}
\hline Contact Point/Diffusion Channel & $\#$ & $\%$ & $\#$ & $\%$ \\
\hline & \multicolumn{2}{|c|}{2017} & \multicolumn{2}{|c|}{2015} \\
\hline Conferences/seminars/courses & 203 & 17.4 & 151 & 22.0 \\
\hline Previous job & 236 & 20.3 & 141 & 20.5 \\
\hline Business media & 293 & 25.2 & 140 & 20.4 \\
\hline Other organisations & 284 & 24.4 & 137 & 19.9 \\
\hline Education & 239 & 20.5 & 134 & 19.5 \\
\hline Consulting firms & 169 & 14.5 & 82 & 11.9 \\
\hline Co-workers & 163 & 14.0 & 64 & 9.3 \\
\hline Lean Forum Norway & 25 & 2.1 & 12 & 1.7 \\
\hline Other & 137 & 11.5 & 73 & 10.6 \\
\hline $\mathbf{N}$ & 1164 & 149.9 & 687 & 135.8 \\
\hline
\end{tabular}

In addition, "other organisations" has moved from fourth to second place. Lean Forum Norge is still the contact point which is least frequently mentioned by the respondents, but this finding could be explained by the fact that this organization's role is as a hub to connect existing and prospective Lean users, as well as a facilitator of different activities with the aim of promoting and sustaining interest in the concept.

\subsection{Adoption Rate}

Table 5 shows the answers to the question: "Has your firm implemented Lean?" The adoption rate among the total number of respondents is 10.8\% (2017), which is a decrease from $11.8 \%$ in 2015 . The adoption rate among those who are aware of Lean is $21.1 \%$ (2017), down from $21.8 \%$. A Z-test ( $Z=$ 0.8135 ) reveals that the decrease is non-significant at the $5 \%$ level.

Table 5. Adoption rate among those who are aware of Lean.

\begin{tabular}{ccccc}
\hline & \multicolumn{2}{c}{$\mathbf{2 0 1 7}$} & \multicolumn{2}{c}{$\mathbf{2 0 1 5}$} \\
\hline Respondents & $\mathbf{N}$ & Adoption (\%) & $\mathbf{N}$ & Adoption (\%) \\
Yes & 238 & 21.1 & 150 & 21.8 \\
No & 874 & 77.3 & 532 & 77.4 \\
Used it previously, but discontinued & 18 & 1.6 & 5 & 0.7 \\
Total & $\mathbf{1 1 3 0}$ & $\mathbf{1 0 0}$ & $\mathbf{6 8 7}$ & $\mathbf{1 0 0}$ \\
\hline
\end{tabular}

The main reason why firms are not adopting Lean is reported to be related to a lack of competence and uncertainty related to its possible effects. Resistance to change is the least common answer. Among the firms that have dropped Lean, we find only private firms. The decrease is significant $(Z=-5.5407)$, even though private firms make up the majority of the respondents. Moreover, $65 \%$ of the former Lean firms can be considered small firms, as they have fewer than 50 employees. The main reasons why the firms have discarded Lean is the lack of management engagement or the costs exceeding the benefits.

\subsection{Adoption Rate in Different Industries}

The two surveys indicate that the adoption rate varies across different industries. The 2017 survey signifies that the adoption rate is highest in traditional industrial production (38\%) and oil, gas and energy (36\%), as well as transport and logistics (24\%). In 2015, the ranking was led by traditional industrial production, followed by finance, accounting and auditing, banking and insurance, and construction. Oil, gas and energy, as well as transport and logistics, have had the most significant increases in their adoption rates, while a decrease can be observed among firms in industries such as finance, accounting, auditing, and construction.

The changes in the adoption rates are, however, different between the private and public sectors (Table 6). The adoption rate is increasing within the public sector, while the opposite is true for the 
private sector. Among the companies that have discontinued their use of Lean (Table 5), there are solely private companies, and the decrease is significant $(Z=-5.5407)$. Moreover, $65 \%$ of former Lean users are small companies (defined, according to NGAAP, as companies with fewer than 50 FTEs). The main reasons for discontinuing Lean were claimed to be the lack of managerial commitment and cost/benefit-considerations.

Table 6. Adopters in the public versus private sector.

\begin{tabular}{ccccc}
\hline & \multicolumn{2}{c}{2017} & \multicolumn{2}{c}{$\mathbf{2 0 1 5}$} \\
\hline Respondents & $\mathbf{N}$ & $\mathbf{\%}$ & $\mathbf{N}$ & $\mathbf{\%}$ \\
Public sector & 20 & 8.4 & 9 & 6.0 \\
Private sector & 207 & 87.0 & 133 & 88.7 \\
Other & 11 & 4.6 & 8 & 5.3 \\
Total & $\mathbf{2 3 8}$ & $\mathbf{1 0 0}$ & $\mathbf{1 5 0}$ & $\mathbf{1 0 0}$ \\
\hline
\end{tabular}

\subsection{Adoption Rate and Organisational Size}

Table 7 describes the relationship between adoption rate and organisational size (measured by number of employees). The decrease in adoption rate from $21.8 \%$ to $21.1 \%$ seems to mostly be related to a decrease among the smallest (from 20 to 11\%) and the largest (from 47.0 to $42.9 \%$ ) firms. The most notable change is among the medium-sized firms (50-99 employees) where there is an increase of $44 \%$ (from 20.2 to $29.1 \%$ ). Combined, the results indicate that there is a strong relationship between adoption rate and organisational size. It will be interesting to monitor whether the decrease in adoption rate among the smallest firms (1-9 employees) will continue and if it is an indication that the success rate of Lean implementations is lower among the smallest firms.

Table 7. Adoption rate and organisational size.

\begin{tabular}{ccccc}
\hline & \multicolumn{2}{c}{$\mathbf{2 0 1 7}$} & \multicolumn{2}{c}{$\mathbf{2 0 1 5}$} \\
\hline Number of employees & $\mathbf{N}$ & Adoption (\%) & $\mathbf{N}$ & Adoption (\%) \\
$1-9$ & 145 & 11.0 & 35 & 20.0 \\
$10-49$ & 641 & 14.2 & 403 & 13.9 \\
$50-99$ & 134 & 29.1 & 94 & 20.2 \\
$100-249$ & 105 & 43.8 & 88 & 42.0 \\
$250+$ & 91 & 42.9 & 66 & 47.0 \\
Do not know & 14 & 50.0 & 1 & 0.0 \\
Total & $\mathbf{1 1 3 0}$ & $\mathbf{2 1 . 1}$ & $\mathbf{6 8 7}$ & $\mathbf{2 1 . 8}$ \\
\hline
\end{tabular}

The slight overall decline in the adoption of Lean (from $21.8 \%$ to $21.1 \%$ ) seems to be rooted in a decline among the smallest (from 20 to $11 \%$ adoption) and largest (from 47.0 to $42.9 \%$ ) firms. The most significant change can be observed among the medium-sized firms (50-99 employees), with an increase amounting to $44.1 \%$ (from 20.2 to $29.1 \%$ ).

\subsection{Future Adoption}

In order to reveal the possible future adoption patterns of Lean, we asked the question: "Do you consider adopting and implementing Lean?" Table 8 shows that approximately five percent of the respondents are planning to use Lean and that more than $60 \%$ say that they have no such plans. Slightly more than $20 \%$ report that they are currently considering adopting and implementing Lean. Even though things can change quickly when it comes to adoption plans, these answers indicate that we are likely not facing a large wave of new Lean users in Norway in the years to come. 
Table 8. Intention to adopt Lean.

\begin{tabular}{ccccc}
\hline & \multicolumn{2}{c}{$\mathbf{2 0 1 7}$} & $\mathbf{2 0 1 5}$ \\
\hline Respondents & $\mathbf{N}$ & Intention (\%) & $\mathbf{N}$ & Intention (\%) \\
Yes & 48 & 5.6 & 33 & 6.2 \\
No & 524 & 61.0 & 333 & 62.6 \\
Under consideration & 194 & 22.6 & 127 & 24.1 \\
Do not know & 93 & 10.8 & 37 & 7.0 \\
Other & 0 & 0.0 & 1 & 0.2 \\
Total & $\mathbf{8 5 9}$ & $\mathbf{1 0 0}$ & $\mathbf{5 3 2}$ & $\mathbf{1 0 0}$ \\
\hline
\end{tabular}

\section{Implementation and Translation}

\subsection{Interpretation and Abstraction Level}

The 2015 survey showed that the respondents differed in their interpretations of Lean, but the questions only scratched the surface in terms of how the concept was interpreted and understood. Therefore, in the 2017 survey, we included several more detailed questions. For example, one question centred on the level of abstraction in the organisation's Lean thinking, which has been a topic of discussion in the Lean literature in recent years. According to Modig and Åhlstrøm [28], a high level of abstraction indicates that Lean is understood as a culture, while a low abstraction level is an indication that it is understood as something much more concrete, i.e. a set of tools and techniques.

The answers in the 2017 surveys show that the respondents have a relatively high level of abstraction when it comes to their Lean thinking (Table 9). Interpretations of Lean as a "way of thinking" and "a way of working" are common and show that the concept to a large degree is more likely to be viewed as a management philosophy or organisational culture than as a management tool. It should, however, be noted that many view Lean as a "method" or "toolbox", which indicates a lower abstraction level. Moreover, it is important to point out that the respondents could mark more than one answer for this question, and most chose to tick several alternatives, which indicates that the respondents ascribe multiple meanings to the Lean concept.

Table 9. Interpretations and translations of Lean in 2017 (more than one option allowed).

\begin{tabular}{ccc}
\hline What is Lean for You? & Number & $\%$ \\
\hline An improvement strategy & 553 & 53.2 \\
A method & 422 & 40.6 \\
A production system & 142 & 13.7 \\
A way of thinking & 392 & 37.7 \\
Values & 85 & 8.2 \\
A philosophy & 211 & 20.3 \\
A toolbox & 329 & 31.6 \\
A way of living & 59 & 5.7 \\
A system of understanding & 98 & 9.4 \\
A strategy & 122 & 11.7 \\
A quality system & 177 & 17.0 \\
Elimination of waste & 382 & 36.7 \\
A way of working & 433 & 41.6 \\
A culture & 284 & 27.3 \\
System thinking & 286 & 27.5 \\
A control system & 233 & 22.4 \\
An approach & 115 & 11.1 \\
Number of respondents & 1040 & \\
\hline
\end{tabular}

On the whole, the results lend some support to research that has shown that Lean has ample room for interpretation and is translated in varied ways when it is put to use in organisations $[2,4,26]$. 
This was also supported by the interview data, which showed that the interviewees had a relatively high abstraction level. All of them mentioned "culture" and "continuous improvement". There also seems to be a relationship between the abstraction level and the length of experience with Lean. One Lean user with more than five years of experience with the concept described Lean in the following way: "Everyone has their own way of improving their own daily work situation." In contrast, those interviewees with less experience emphasise concrete Lean tools when asked to describe Lean. Consider the following quote: "My understanding of Lean is: process improvements, customer focus, scorecards, constant measurement of Key Performance Indicators, the more the better."

\subsection{Lean principles}

Table 10 shows the firms' use of Lean-related principles. In developing this question, we drew on both the five principles identified by Womack and Jones [53] and the 14 principles of Lean identified by Liker [54]. Liker's principles are partially overlapping with the Womack and Jones, but focus slightly more on waste and the identification of problems, as well as the human side of the process [9].

Table 10. Use of Lean principles.

\begin{tabular}{cccccc}
\hline Lean principle & Frequency & Percentage & Frequency & Percentage \\
\hline Value & & $\mathbf{2 0 1 7}$ & & $\mathbf{2 0 1 5}$ \\
Value stream & 31 & 14.7 & 22 & 14.7 \\
Flow & 98 & 46.4 & 57 & 38.0 \\
Pull & 125 & 59.2 & 82 & 54.7 \\
Continuous improvement (Kaizen) & 47 & 22.3 & 22 & 14.7 \\
Heijunka & 164 & 77.7 & 117 & 78.0 \\
Right first time & 58 & 27.5 & 26 & 17.3 \\
Standardisation & 116 & 55.0 & 86 & 57.3 \\
Visual control & 132 & 62.6 & 102 & 68.0 \\
Do not know & 72 & 34.1 & 48 & 32.0 \\
\# Respondents & 5 & 2.4 & & \\
\hline
\end{tabular}

The most commonly used principles were continuous improvement, standardisation, flow and right first time. More than half of the respondents reported that they used these principles. The principle of value is notably the least frequently used. These findings are consistent across the two surveys, and generally support Rolfsen [9] who found that the principles of standardization, flow and continuous improvement are commonly used in Norway.

While the findings in the previous section suggest that there is a lack of consistent definition of the Lean concept, some Lean principles have achieved a strong foothold and become strongly associated with the use of the Lean concept in Norway.

\subsection{Lean Tools and Techniques}

Table 11 displays the extent to which the respondents use different Lean tools and techniques in their firm. In formulating this question, we consulted different books on Lean to identify possible tools and techniques $[9,28,55,56]$. In the 2017 survey, we added some additional tools which have been the focus of past writings on Lean in Norway [9]. It should be noted that it is highly debatable whether Six Sigma is a Lean tool [57]. However, Six Sigma still shares some similarities with Lean in that it aims to enhance capabilities and reduce variability [9], and other authors point out that Six Sigma-related tools can be used within the framework of Lean [56], p. 23. 
Table 11. Use of Lean tools and techniques (more than one option allowed).

\begin{tabular}{cccc}
\hline Lean Tool/Technique & Average & $\mathbf{2 0 1 7}$ & $\mathbf{2 0 1 5}$ \\
\hline Visual boards & 5.57 & 5.60 & 5.52 \\
Standardised work & 5.45 & 5.22 & 5.77 \\
processes & & & \\
5S & 5.15 & 5.07 & 5.26 \\
Visual management & 5.15 & 5.07 & 5.25 \\
Identification of waste & 4.99 & 4.82 & 5.19 \\
PDCA wheel & 4.69 & 4.90 & 4.41 \\
5 Whys & 4.61 & 4.59 & 4.63 \\
A3 & 4.39 & 4.70 & 3.99 \\
Value stream mapping & 4.30 & 4.24 & 4.37 \\
Gemba walks & 3.97 & 3.97 & 3.97 \\
Kanban & 3.90 & 4.01 & 3.78 \\
SMED & 3.17 & 3.37 & 2.99 \\
Poka-Yoke & 3.02 & 3.23 & 2.83 \\
Total productive & 2.96 & 3.20 & 2.74 \\
maintenance & & & \\
Removal of bottlenecks & & 5.12 & n/a \\
Just-in-Time & & 4.00 & n/a \\
Quality circles & & 3.74 & n/a \\
Statistical process control & & 3.64 & n/a \\
Six Sigma & & 3.44 & n/a \\
\# Respondents & $\mathbf{3 6 2 5}$ & $\mathbf{2 1 7 4}$ & $\mathbf{1 4 5 1}$ \\
\hline
\end{tabular}

Overall, the data show that there is a high level of consistency in the use of different tools and techniques in the period 2015-2017. The data in the table indicate that most parts of the Lean toolbox are used to a large degree (mean values around 5). In particular, tools such as visual boards, 5S, standardised work processes and visual management are frequently used (mean values above 5).

\section{Effects}

\subsection{Aim}

The main reason (75\%) organisations reported for implementing Lean is to make better use of resources and enhance productivity. Improved financial results and enhanced quality are ranked joint second and third, with approximately $52 \%$ each; increased employee satisfaction and customer satisfaction both exceed $49 \%$. The overall picture is the same when it comes to both those who have implemented Lean and those planning to implement it. There have not been any notable changes in the period spanning 2015 to 2017.

\subsection{Perceived Effects}

In both 2015 and 2017, the respondents reported that they perceived very positive effects of Lean. In the 2017 survey, $83 \%$ of respondents claimed that they had observed such positive effects. The strongest effect is reported to be increased quality, followed by increased employee satisfaction. In both 2015 and 2017, very few respondents reported negative experiences with Lean.

Among the interviewees, it was claimed that Lean was not implemented to save money, even though the implementation took place at approximately the same time as downsizing initiatives. However, the interviewees argued that they would expect to experience less resistance if the implementation of Lean happens during favourable economic times.

\subsection{Reduction of Waste}

Reduction of waste (muda) is an important issue covered in the Lean literature and is considered one of the main goals of Lean [54]. The surveys confirm that the firms experience positive effects as a 
result of implementing Lean. Wait times in production processes are seen as particularly unnecessary as these contribute to waste. Furthermore, the reduction of errors and unnecessary movements are areas where users report having the best results from Lean implementation.

We studied eight categories of muda. We controlled the reliability by running a Cronbach Alpha test and found an internal consistency of 0.87, which we consider acceptable. In both 2015 and 2017, there were four dominant areas of waste (a Likert-scale 1-7 applied): waiting time (4.8 vs 5.1), unnecessary motion (5.0 vs 5.0), insufficient use of human capital (4.7 vs 4.9$)$ and errors and deviations (4.7 vs 4.7 ).

In the interviews, all interviewees reported being concerned with waste and claimed to have reduced waste as a result of continuous process improvements. This was also mentioned as one of the most important reasons for adopting and implementing Lean.

\subsection{Implementation Challenges}

We also asked the respondents about what they perceived to be the most significant challenges associated with the use of Lean; $39.6 \%$ reported a lack of capacity as the most important obstacle on the road to becoming Lean, followed by cultural challenges (39.2\%). Moreover, 32.1\% reported a lack of motivation among employees. One of the interviewees said, "We would like [to] develop a Lean culture. We are not there today. We need to allocate time to it and dig down into the details, but we don't have time for that!" All of the interviewees reported experiencing start-up problems since they had to change both their current ways of thinking and the associated culture, which they found to be challenging.

The implementation was particularly difficult in cases where there was a lack of commitment and understanding from top management. One of the interviewees characterised the early phase of the implementation process as a "muddy" phase. However, over time, the resistance decreased. As one of the interviewees said, "At first, people were sceptical, but over time they have embraced the tools. In the beginning, they felt like the new forms and methods created additional stress and that it was tiring. However, then they have got them under their skin. Lean is now with them all the time, and not just something you do at a certain time."

Among those who report having used Lean in the past, a lack of capacity is mentioned as the most common reason for discarding the concept (55\%). In addition, almost half report a lack of management commitment as a reason. It should, however, be noted that there was a low number of respondents (18) in the "ex-users of Lean" category.

In 2015, the most important reasons for not implementing Lean were the use of other management concepts and tools and a lack of knowledge and competence. In 2017, a lack of knowledge and competence, as well as uncertainty about the effects of Lean, were the most important reasons. In both surveys, resistance to change was the least important reason. It should also be noted that in $201711.7 \%$ reported that they use parts of the Lean concept without calling it Lean.

\section{Discussion}

\subsection{Diffusion}

The results show that the evolutionary pattern of Lean in Norway differs from what has been observed in some other countries. While Bain \& Company's studies indicate that the worldwide popularity of Lean has dipped considerably in the last decade, our findings suggest that the diffusion and popularity of Lean in Norway is relatively stable.

Overall, the two surveys indicate that the awareness of Lean is moderately high and that the majority of respondents claim to be aware of Lean. Moreover, the adoption rate is relatively stable during the study period. Even though there is a small decrease in the adoption rate, this change is non-significant. The number of firms that have used Lean for more than 10 years has also increased, 
which may indicate that Lean has gained a relatively strong foothold in Norway as a well-established way of managing and governing firms.

What factors are able to explain the idiosyncratic Norwegian evolutionary trajectory? One important component is the establishment of the Lean Forum Norway which, since its inception in 2010, has played an essential role in creating and fostering the Lean movement in Norway by acting as a hub connecting current and prospective Lean users and creating a close-knit community with a strong shared identity $[3,23]$.

The relatively quick rise of Lean in Norway can also be attributed to a vastly active supply side promoting and disseminating Lean (e.g., the high number of consulting firms offering Lean-related services in the Norwegian market). These actors have popularised the concept, educated prospective users and facilitated its use in practice. Our results clearly show that most of the Lean users have come into contact with the Lean concept via diffusion channels such as consultant firms, business media, Lean courses, conferences and contact with other organisations. This indicates that institutional and social factors (e.g., fashion/fad pressure; $[58,59]$ could have played a role in the pandemic spread of Lean in Norway in recent years [11].

\subsection{Use and Effects}

The results clearly demonstrate that there is much variation in terms of how Lean is interpreted and used in practice, and this serves as an illustration of the interpretive space of the Lean concept $[2,4,27]$. There are quite significant differences in terms of precisely what is being implemented under the Lean label, both when it comes to the abstraction level and the use of different Lean principles and tools.

The results illustrate that there are clear views and expectations about the effects of implementing Lean. In both surveys, the respondents generally have a decidedly positive view of Lean. Most perceive Lean to have positive or very positive effects on areas such as quality, employee and customer satisfaction, productivity and flexibility. Although we only have self-reported perceptual data about the effects of Lean, it is possible that the adoption and implementation of Lean leads to less waste, improved customer satisfaction, and improved production processes, which ultimately could lead to improvements in financial performance.

It is striking that almost nobody (in both 2015 and 2017) is negative about the concept. This could indicate that there is a still level of euphoria and religiousness among members of the Lean community in Norway. Very strong beliefs in the merits of different management concepts have previously been observed in studies of concepts such as Quality Management and Lean [60,61]. For example, Oliver (2008) shows that the language used in discussions about Lean resembles what is typically found in religious communities, and that criticism of the Lean methods are viewed by followers as blasphemous. In a similar vein, Sørhaug [60], s. 159 notes that people who criticise Lean have to be prepared to face an overbearing reaction from believers. The critical voice who dares to speak up will typically hear that the problems are due to an incomplete implementation process and that any issues will disappear once this process is complete. As Sørhaug notes, there is rarely, if ever, anything wrong with Lean as a concept. Instead, the problems are attributed to users' lack of understanding and their (incorrect) application [60].

\subsection{Long-term Sustainability}

The results also provide some insight into the sustainability of Lean. As discussed in Section 2, when discussing Lean and sustainability, it is possible to refer to both the concept's links with ecological and environmental sustainability, and the sustainability of the Lean concept itself [31]. Although the findings of the surveys show that the respondents report that the use of Lean has a number of positive effects, e.g., in terms of reducing waste, the main focus of the current paper has not been on how Lean can be used to improve ecological or environmental sustainability. Rather, the focus has been on the sustainability of the Lean concept itself. 
Generally, the surveys show that the respondents have predominantly positive perceptions of Lean, suggesting that the concept stands a good chance of keeping its current level of interest and momentum in Norwegian organization for some time, and perhaps long enough for organizations to "learn to be lean" and develop necessary capabilities to capitalize on its potential benefits [31,38,39], which would further institutionalize the concept as a sustainable management practice in Norwegian organizations.

A key question, however, remains whether the predominantly positive view of Lean will persist when the concept reaches the later stage of its life cycle in Norway. Analyses of previous research on the implementation effects of Lean show that the results are often not able to meet the (perhaps) overly high expectations [62]. Our two surveys indicate that implementing Lean is not always easy and straightforward. For example, in Section 6.4 we saw that the respondents, even though they had a very positive view of Lean, admit that there are many challenges associated with the implementation of Lean e.g., [39,43].

From research on the implementation of management concepts, we know that a considerable share of users never succeeds in the "translation" process, i.e. contextualising a concept so that it fits with the organisation's needs and circumstances $[63,64]$. The occurrence, therefore, of disappointed or disgruntled ex-Lean users in Norway is nearly unavoidable. As a result, it will be fascinating to continue to monitor the evolutionary trajectory of Lean in Norway, and see whether implementation problems and negative experiences enter the Lean's public media discourse, which often happens as a management concept loses some of its lustre and enters the later stages of its life cycle [65]. How these processes play out will influence the long-term sustainability of Lean in the Norwegian context.

\section{Conclusion}

\subsection{Theoretical Implications}

The findings of this article have vital implications for research on the diffusion and use of management concepts such as Lean. First of all, the empirical data showcase that management concepts may have country-specific evolutionary trajectories [4]. The evolutionary trajectory of Lean in Norway differs from what has been seen in other countries both in terms of its diffusion and use. In particular, the evidence suggests that Lean "took off" at a later stage in Norway than in countries such as Sweden [5] and Germany [4]. Today, the popularity of Lean appears to be quite a bit higher in Norway than on the world stage, according to Bain \& Company's ranking of management tools [2]. The very high level of enthusiasm and satisfaction among Lean users also suggests that the concept may have a degree of long-term sustainability in Norway. However, the future durability of Lean in Norway is ultimately an empirical question for future research.

The study also showcases much variation in terms of how the Lean concept is interpreted and used in Norway. This provides support for studies that have shown that the Lean concept has attained a Norwegian flavour as a result of encountering Norwegian work-life and business culture [20,21]. Therefore, in order to provide information about the local evolutionary trajectory and sustainability of a management concept such as Lean, it is crucial to not only look at surface-level diffusion patterns but also dig deeper and to examine variations in its interpretations and usage over time.

\subsection{Methodological Implications}

In our view, the study also has methodological implications. There are a number of methodological challenges and opportunities related to the study of the diffusion and use of management concepts such as Lean. In general, due to their ideational nature [65], management concepts can be very difficult to study methodologically [66]. In the popular management concepts and ideas literature, there are generally few studies which have examined patterns in the use of management concepts; even rarer are longitudinal studies. One important exception is the aforementioned Bain \& Company study of management tools and trends, which has been carried out since the 1990s, but it should be noted that this survey utilises relatively simple questions about adoption and satisfaction, and does not 
really delve into questions about how respondents interpret, understand and use specific management concepts. Our empirical data about Lean show that there is substantial variation in terms of its interpretation and use, which means that such "check the box" survey questions provide little insight into what is actually diffused under the Lean label. This is an even bigger issue when taking into account that concepts are interpreted differently when they are spread across national, regional and cultural boundaries.

\subsection{Limitations and Ideas for Future Research}

The usual limitations of survey research apply in this study as well. The most glaring limitation of this study is its low-response rate, which leads to issues related to non-response bias. There may also be challenges related to the use of pre-defined questions and answer alternatives. Another potential issues is so-called "common method bias" [67,68]. For example, it is possible that some of the variation in responses about interpretation and understanding of Lean observed in this study could be caused by the survey instrument.

In addition, we have also only been able to obtain the view of one respondent per organisation, and this respondent's views may not be representative of the rest of the organisation. Many of the respondents, and in particular the respondents who were willing to participate in a follow-up interview, may have provided a biased view since they are typically Lean enthusiasts; it may, therefore, be in their best interest to paint a rosy picture of the implementation process. In the management concepts literature, it has been noted that individuals who have participated in the introduction of a new concept will usually be in a "honeymoon phase" where they are not able to critically reflect on the concept and its process cf. [69], p. 213.

As potential study extensions, there are two areas which look particularly promising. First of all, it would be interesting to carry out another replication to monitor the evolutionary trajectory of Lean over time. Our study has shown that the evolutionary pattern in Norway differs from what is seen internationally. While Lean fell out of Bain \& Company's top 25 ranking about ten years ago [6,7], in Norway Lean remains "hot" and very much in vogue. This suggests that the evolutionary trajectory of Lean varies across time and space, and that the concept of Lean is more sustainable in some geographical and cultural contexts and at certain time periods than others. Therefore, it will be interesting to monitor the future popularity trajectory of Lean in Norway. Will Lean continue to attract interest and followers in Norway or will we see a dip in popularity? Such examinations could contribute to our knowledge about the cross-national impact of popular management concepts and ideas $[4,70]$.

Even though studies of management concepts are difficult and costly to carry out in practice, there is a need for cross-national comparative studies of the evolutionary pattern of Lean. For example, researchers could design a study of two or more countries, where data are gathered by means of surveys and mini case studies, as well as by mapping the activities of local actors and institutions. This way, researchers could potentially distil the relative importance of local and global factors in shaping the local evolutionary trajectory of management concepts and ideas, as well as their role in the institutionalization of concepts and ideas as long-term sustainable management practices.

Author Contributions: Conceptualization, M.S, J.V.M., I.O.B., T.B. and D.Ø.M; methodology, M.S., J.V.M and I.O.B; formal analysis, T.B., M.S., J.V.M. and I.O.B.; investigation, M.S., J.V.M. and I.O.B.; data curation, T.B., M.S., J.V.M. and I.O.B.; writing—original draft preparation, D.Ø.M; T.B. and T.S; writing—review and editing, D.Ø.M and T.S.; supervision, D.Ø.M. and T.B.; project administration, D.Ø.M.

Funding: The APC was funded by University of South-Eastern Norway's Open Access Fund.

Acknowledgments: The authors would like to thank four anonymous reviewers for valuable comments.

Conflicts of Interest: The authors declare no conflict of interest. 


\section{References}

1. Womack, J.P.; Jones, D.T.; Roos, D. The Machine That Changed the World; Simon and Schuster: New York, NY, USA, 1990.

2. Wittrock, C. Reembedding Lean: The Japanese Cultural and Religious Context of a World Changing Management Concept. Int. J. Sociol. 2015, 45, 95-111. [CrossRef]

3. Benders, J.; van Grinsven, M.; Ingvaldsen, J. The Persistence of Management Ideas; How Framing Keeps Lean Moving. In The Oxford Handbook of Management Ideas; Sturdy, A., Stefan, H., Rey, H.T., Strang, D., Eds.; Oxford University Press: Oxford, UK, 2019; pp. 271-285.

4. Benders, J.; van Bijsterveld, M. Leaning on Lean: The Reception of Management Fashion in Germany. New Technol. Work Employ. 2000, 15, 50-64. [CrossRef]

5. Larsson, E. Managementmoden och popularitetssvängningar-En studie av Lean-konceptet $i$ svensk populärpress 1990-2008; University of Gothenburg: Gothenburg, Sweden, 2012; Available online: http://hdl.handle.net/ 2077/28467 (accessed on 16 February 2019).

6. Rigby, D.; Bilodeau, B. Bain's Global 2007 Management Tools and Trends Survey. Strategy Leadersh. 2007, 35, 9-16. [CrossRef]

7. Rigby, D.; Bilodeau, B. Management Tools \& Trends 2009; Bain \& Company: London, UK, 2009.

8. Rigby, D.; Bilodeau, B. Management Tools E Trends; Bain \& Company, Inc.: Boston, MA, USA, 2018.

9. Rolfsen, M. Lean Blir Norsk: Lean i den norske samarbeidsmodellen; Fagbokforlaget: Bergen, Norway, 2014.

10. Ingvaldsen, J.; Rolfsen, M.; Finsrud, H. Lean organisering i norsk arbeidsliv: Slutten på medvirkning? Magma 2012, 2, 42-50.

11. Aspøy, A. Lean tar over styringen. Stat Styr. 2014, 24, 1. Available online: https://www.idunn.no/stat/2014/ 04/lean_tar_over_styringen (accessed on 15 January 2019).

12. Kalsaas, B.T. Lean Construction. Forstå Og Forbedre Prosjektbasert Produksjon; Fagbokforlaget: Bergen, Norway, 2017.

13. Andersen, H.; Røvik, K.A. Lost in Translation: A Case-Study of the Travel of Lean Thinking in a Hospital. BMC Health Serv. Res. 2014, 15, 401. [CrossRef] [PubMed]

14. Gravdal, S.I.; Waagø-Hansen, M. Coalition for Change-How Lean Is Interpreted and Entrenched in Norwegian Industry. Master's Thesis, Norwegian University of Science and Technology, Trondheim, Norway, 2018. Available online: https://ntnuopen.ntnu.no/ntnu-xmlui/handle/11250/2576679 (accessed on 15 March 2019).

15. Johnstad, T.; Giæver, T.; Holtskog, H.; Strand, T. Lean på norsk: Med erfaringer fra Raufoss-industrien; Oplandske bokforlag: Vallset, Norway, 2012.

16. Ringen, G.; Rolfsen, M. Lean Kommune. In Lean blir norsk: Lean i den norske samarbeidsmodellen; Rolfsen, M., Ed.; Fagbokforlaget: Bergen, Norway, 2014; pp. 118-189.

17. Madsen, D.Ø.; Risvik, S.; Stenheim, T. The Diffusion of Lean in the Norwegian Municipality Sector: An Exploratory Survey. Cogent Bus. Manag. 2017, 4, 1411067. [CrossRef]

18. Dolva, M.M. Implementering av Lean i norske kommuner: Har norske kommuner implementert Lean, eller vurderer de å implementere det? Master's Thesis, University of Agder, Kristiansand, Norway, 2011.

19. Schie, I. Lean i norske kommuner: En studie om spredning av Lean som styringsverktøy, og endringer i organisasjonen som en følge av implementeringen. Master's Thesis, University of Agder, Kristiansand, Norway, 2012.

20. Ingvaldsen, J.; Ringen, G.; Rolfsen, M. Lean på global vandring. In Lean blir norsk: Lean $i$ den norske samarbeidsmodellen; Rolfsen, M., Ed.; Fagbokforlaget: Bergen, Norway, 2014; pp. 33-47.

21. Hagedorn-Rasmussen, P.; Klethagen, P. International Management Concepts Meeting Nordic Working Life. In Work and Wellbeing in the Nordic Countries: Critical Perspectives on the World's Best Working Lives; Hvid, H., Falkum, E., Eds.; Routledge: Abingdon-on-Thames, UK, 2018.

22. Langstrand, J. Exploring Organizational Translation: A Case Study of Changes toward Lean Production. Ph.D. Thesis, Linköping University, Linköping, Sweden, 2012.

23. Madsen, D.Ø.; Storsveen, M.; Klethagen, P.; Stenheim, T. The Diffusion and Popularity of Lean in Norway: An Exploratory Survey. Cogent Bus. Manag. 2016, 3, 1258132. [CrossRef]

24. Holweg, M. The Genealogy of Lean Production. J. Oper. Manag. 2007, 25, 420-437. [CrossRef]

25. Krafcik, J.F. Triumph of the Lean Production System. MIT Sloan Manag. Rev. 1998, 30, 41-52. 
26. Brännmark, M.; Langstrand, J.; Johansson, S.; Halvarsson, A.; Abrahamsson, L.; Winkel, J. Researching Lean: Methodological Implications of Loose Definitions. Qual. Innov. Prosper. 2012, 16, 35-48. [CrossRef]

27. Langstrand, J.; Drotz, E. The Rhetoric and Reality of Lean: A Multiple Case Study. Total Qual. Manag. Bus. Excell. 2016, 27, 398-412. [CrossRef]

28. Modig, N.; Åhlström, P. Detta Är Lean; Rheologica Publishing: Stockholm, Sweden, 2014.

29. Ingvaldsen, J.A. Democratic Lean? Work Systems in Norwegian Industry; Institutt for Industriell Økonomi og Teknologiledelse: Trondheim, Norway, 2013.

30. Rolfsen, M.; Ingvaldsen, J. Unions and the Lean Concept. In Proceedings of the ILPC Conference, Stockholm, Sweden, 27-29 March 2012; Available online: https://www.ilpc.org.uk/Portals/56/ilpc2012-paperupload/ ILPC2012paper-Unions\%20and\%20the\%20Lean\%20concept\%20-\%20manuskript_20120318_082821.pdf (accessed on 15 October 2018).

31. Jørgensen, F.; Matthiesen, R.; Nielsen, J.; Johansen, J. Lean Maturity, Lean Sustainability; Springer: Boston, MA, USA, 2007.

32. Martínez-Jurado, P.J.; Moyano-Fuentes, J. Lean Management, Supply Chain Management and Sustainability: A Literature Review. J. Clean. Prod. 2014, 85, 134-150. [CrossRef]

33. Cherrafi, A.; Elfezazi, S.; Chiarini, A.; Mokhlis, A.; Benhida, K. The Integration of Lean Manufacturing, Six Sigma and Sustainability: A Literature Review and Future Research Directions for Developing a Specific Model. J. Clean. Prod. 2016, 139, 828-846. [CrossRef]

34. Chiarini, A. Sustainable Manufacturing-Greening Processes Using Specific Lean Production Tools: An Empirical Observation from European Motorcycle Component Manufacturers. J. Clean. Prod. 2014, 85, 226-233. [CrossRef]

35. Fliedner, G.; Majeske, K. Sustainability: The New Lean Frontier. Prod. Inventory Manag. J. 2010, 446, 6-13.

36. Piercy, N.; Rich, N. The Relationship between Lean Operations and Sustainable Operations. Int. J. Oper. Prod. Manag. 2015, 35, 282-315. [CrossRef]

37. Dhingra, R.; Kress, R.; Upreti, G. Does Lean Mean Green? J. Clean. Prod. 2014, 85, 1-7. [CrossRef]

38. Boyle, A.T.; Scherrer-Rathje, M.; Stuart, I. Learning to Be Lean: The Influence of External Information Sources in Lean Improvements. J. Manuf. Technol. Manag. 2011, 22, 587-603. [CrossRef]

39. Scherrer-Rathje, M.; Boyle, T.A.; Deflorin, P. Lean, Take Two! Reflections from the Second Attempt at Lean Implementation. Bus. Horiz. 2009, 52, 79-88. [CrossRef]

40. Achanga, P.; Shehab, E.; Roy, R.; Nelder, G. Critical Success Factors for Lean Implementation within Smes. J. Manuf. Technol. Manag. 2006, 17, 460-471. [CrossRef]

41. Sim, K.L.; Rogers, J.W. Implementing Lean Production Systems: Barriers to Change. Manag. Res. News 2008, 32, 37-49. [CrossRef]

42. Bhasin, S.; Burcher, P. Lean Viewed as a Philosophy. J. Manuf. Technol. Manag. 2006, 17, 56-72. [CrossRef]

43. Bhasin, S. Prominent Obstacles to Lean. Int. J. Product. Perform. Manag. 2012, 61, 403-425. [CrossRef]

44. Bhasin, S. An Appropriate Change Strategy for Lean Success. Manag. Decis. 2012, 50, 439-458. [CrossRef]

45. Moum, J.V.; Bordewich, I.O. Lean-glasur eller ingrediens? En studie av hvordan styringsverktøy oversettes og implementeres eksemplifisert gjennom en studie av Lean i Norge. Master's Thesis, Norwegian University of Science and Technology, Trondheim, Norway, 2017. Available online: https://ntnuopen.ntnu.no/ntnuxmlui/handle/11250/2488185 (accessed on 16 February 2019).

46. Storsveen, M. Utbredelsen av Lean i Norge: En spørreundersøkelse. Master's Thesis, Norwegian University of Life Sciences, Ås, Norway, 2016. Available online: https://nmbu.brage.unit.no/nmbu-xmlui/handle/11250/ 2379731 (accessed on 16 February 2019).

47. Ghauri, P.; Grønhaug, K. Research Methods in Business Studies, 2nd ed.; FT Prentice Hall: Harlow, UK, 2002.

48. Jansen, J.K.; Corley, K.G.; Jansen, B.J. E-Survey Methodology. In Handbook of Research on Electronic Surveys and Measurements; Reynolds, R.A., Woods, R., Eds.; Idea Group Reference: Hershey, PA, USA, 2007; pp. $416-425$.

49. Mitchell, M.; Jolley, J. Research Design Explained; Cengage Learning: Boston, MA, USA, 2012.

50. Cook, C.; Heath, F.; Thompson, R.L. A Meta-Analysis of Response Rates in Web-or Internet-Based Surveys. Educ. Psychol. Meas. 2000, 60, 821-836. [CrossRef]

51. Shih, T.-H.; Fan, X. Comparing Response Rates from Web and Mail Surveys: A Meta-Analysis. Field Methods 2008, 20, 249-271. [CrossRef]

52. Porter, R.S.; Whitcomb, M.E.; Weitzer, W.H. Multiple Surveys of Students and Survey Fatigue. New Dir. Inst. Res. 2004, 121, 63-73. [CrossRef] 
53. Womack, P.J.; Jones, D.T. Lean Thinking, 2nd ed.; Free Press: New York, NY, USA, 2003.

54. Liker, J.K. The Toyota Way-14 Management Principles from the World's Greatest Manufacturer; McGraw-Hill: New York, NY, USA, 2004.

55. Modig, N.; Åhlström, P. This Is Lean: Resolving the Efficiency Paradox; Rheologica Publishing: Stockholm, Sweden, 2012.

56. Sayer, N.J.; Williams, B. Lean for Dummies; John Wiley \& Sons: Hoboken, NJ, USA, 2012.

57. Antony, J. Six Sigma Vs Lean: Some Perspectives from Leading Academics and Practitioners. Int. J. Prod. Perform. Manag. 2011, 60, 185-190. [CrossRef]

58. Abrahamson, E. Managerial Fads and Fashions: The Diffusion and Rejection of Innovations. Acad. Manag. Rev. 1991, 16, 586-612. [CrossRef]

59. Røvik, K.A. Moderne organisasjoner; Fagbokforlaget: Oslo, Sweden, 1998.

60. Sørhaug, T. Gull, arbeid og galskap: Penger og objekttrøbbel; Fagbokforlaget Vigmostad og Bjørke: Oslo, Sweden, 2016.

61. Oliver, N. Rational Choice or Leap of Faith? The Creation and Defence of a Management Orthodoxy. Learn. Organ. 2008, 15, 373-387. [CrossRef]

62. Stentoft Arlbjørn, J.; Vagn Freytag, P. Evidence of Lean: A Review of International Peer-Reviewed Journal Articles. Eur. Bus. Rev. 2013, 25, 174-205. [CrossRef]

63. Røvik, K.A. Trender og translasjoner-Ideer som former det 21. århundrets organisasjon; Universitetsforlaget: Oslo, Norway, 2007.

64. Örtenblad, A. Handbook of Research on Management Ideas and Panaceas: Adaptation and Context; Edward Elgar Publishing: Cheltenham, UK, 2015.

65. Benders, J.; van Veen, K. What's in a Fashion? Interpretative Viability and Management Fashions. Organization 2001, 8, 33-53. [CrossRef]

66. Strang, D.; Wittrock, C. Methods for the Study of Management Ideas. In Oxford Handbook of Management Ideas; Sturdy, A., Heusinkveld, H.S., Rey, T., Strang, D., Eds.; Oxford University Press: Oxford, UK, 2019.

67. Kamakura, W.A. Common Methods Bias. Wiley Int. Encycl. Mark. 2010. [CrossRef]

68. Doty, H.D.; Glick, W.H. Common Methods Bias: Does Common Methods Variance Really Bias Results? Organ. Res. Methods 1998, 1, 374-406. [CrossRef]

69. Malmi, T. Balanced Scorecards in Finnish Companies: A Research Note. Manag. Acc. Res. 2001, 12, $207-220$. [CrossRef]

70. Madsen, D.; Slåtten, K. The Role of the Management Fashion Arena in the Cross-National Diffusion of Management Concepts: The Case of the Balanced Scorecard in the Scandinavian Countries. Adm. Sci. 2013, 3, 110-142. [CrossRef] 